\title{
La regulación de la economía y los programas legislativos 2000-2003 de ARENA y el FMLN
}

En los últimos tiempos se ha generado cada vez mayor discusión sobre el papel de la regulación económica en modelos económicos, donde la principal consigna es la liberalización económica. Aunque aún pueden encontrarse extremistas que proponen una regulación desaforada de las empresas 0 , todo lo contrario, una liberalización total de la actividad económica aun y cuando existan muestras evidentes de sus efectos nocivos. En la actualidad, y afortunadamente, la discusión ya no se centra en si la regulación es necesaria o no, sino más bien en cuáles son los niveles adecuados de regulación para armonizar la eficiencia del libre mercado con los objetivos del desarrollo sostenible.

En Chile, por ejemplo, que es catalogado como el paradigma de los modelos neoliberales, existen severas regulaciones que afectan a las empresas de los sectores económicos claves, como el eléctrico, telefónico y agua, sobre las cuales pesan regulaciones de fijación de tarifas que, en algunos casos, las obliga a disminuirlas. Sin embargo, el sector más regulado es el del medio ambiente, donde las empresas industriales deben someterse a severas medidas de control de sus emisiones.

En El Salvador, la discusión sobre la regulación y el papel del Estado en la economía se ha reactivado con la difusión del programa legislativo del FMLN para las elecciones de diputados y alcaldes, a celebrarse en este mes de marzo, en el cual se propone configurar un modelo económico "alternativo al esquema neoliberal" y que contem- pla regulaciones y otras políticas económicas que vengan a solucionar algunos de los principales problemas económicos del país.

Aunque ARENA también ha presentado su propio programa legislativo, éste no ha despertado mayores comentarios ni de parte de los empresarios ni de parte del sector laboral, debido a que, como se muestra más adelante, es tan general y "políticamente correcto" que resulta difícil y hasta atrevido cuestionar programas que insisten en buscar la superación de la pobreza; a lo sumo puede señalarse que el programa de ARENA es demagógico porque ignora la grave problemática económica actual y, por lo mismo, no propone medidas correctivas que a estas alturas ya son urgentes. Por lo anterior, no debe extrañar que, en buena medida, el presente comentario se centre más en la propuesta del FMLN, por ser ésta la que presenta propuestas que, aunque discutibles, pueden orientar la discusión de medidas de política económica apropiadas para la realidad salvadoreña.

Lo primero que llama la atención al revisar las dos diferentes propuestas es que ARENA mantiene, sin mayores cambios, sus ofertas económicas, centrándose en la tarea de generar empleo e ingresos como la única vía para lograr una reducción de la pobreza; el FMLN, en cambio, sí propone cambios significativos en la conducción económica, especialmente porque propone una mayor intervención del Estado en la regulación de variables y actividades económicas. En lo que sigue, se presentan 
los elementos principales de las plataformas electorales presentadas tanto por ARENA como por el FMLN, algunas de las primeras reacciones que se han manifestado frente a ellas -que sólo atañen al FMLN - y algunas consideraciones sobre la problemática económica actual y posibles soluciones a la misma.

\section{Los programas legislativos en materia económica}

La propuesta económica del FMLN para la próxima legislatura contempla -como se mencionó- la implementación de medidas tendientes a la conformación de un modelo económico "alternativo", el cual contemplaría medidas como la de implementar mecanismos que garanticen un funcionamiento del mercado que preserve los intereses sociales mayoritarios, priorizar la demanda intema y regional, promover el respeto a la propiedad privada y cooperativa en función social, combinar la apertura del mercado mundial con la protección de los sectores productivos y apoyar a la micro y pequeña empresa, para mencionar algunas de las propuestas más destacables.

La visión del FMLN se resume bien cuando en su propuesta legislativa considera las' funciones del Estado: dinamizar el desarrollo sustentable, crear obras y empresas estratégicas, redistribuir el ingreso nacional-y buscar la equidad social. Lo anterior supone la necesidad de que el Estado se convierta en un agente activo en la búsqueda del desarrollo, a diferencia del enfoque del partido ARENA, donde el Estado no juega un papel protagónico y su función se limita a eliminar trabas para el "libre juego de las fuerzas del mercado", erróneamente consideradas como la panacea para los problemas del desarrollo.

Algunas medidas "urgentes" que plantea el FMLN para hacer frente a la crisis económica son: declarar una ley moratoria temporal para suspender la ejecución de embargos, apertura de líneas de crédito para agricultores y pequeños empresarios a tasas preferenciales, facultar al Banco Central de Reserva para fijar las tasas de interés, adoptar una política cambiaria flexible, abandonar la "desgravación unilateral", fortalecer la banca de desarrollo, detener las privatizaciones, regular las utilidades de las empresas de electricidad y telefonía, combatir el déficit fiscal combatiendo la evasión y reformando el sistema tributario para que paguen "más impuestos quienes reciben más ingresos", reducir el Impuesto al Valor Agregado
(IVA) del 10 al 13 por ciento y promover la descentralización de la administración pública. Cabe señalar, finalmente, que dentro de la propuesta se encuentran también planes de desarrollo sectorial para los sectores rural e industrial.

El partido ARENA, por su parte, se propone generar más empleo e ingresos a través de la "promoción de actividades productivas que ofrezcan más empleos; mejorar el marco institucional que permita una relación amoniosa entre trabajadores y empleadores; reducir la pobreza al aumentar los ingresos; y aprobar oportunamente el presupuesto general de la nación en función de la satisfacción de las necesidades más sentidas de la población". Los campos de acción del programa de ARENA serían: el fortalecimiento del marco legal para fomentar más inversión nacional y extranjera que generen empleo, la legislación para el desarrollo agroindustrial y agroturístico para erradicar la pobreza rural, el apoyo al desarrollo de la micro y pequeña empresa, el fomento de las exportaciones, el aprendizaje para la superación de la juventud y, finalmente, la responsabilidad presupuestaria

En la parte titulada "Compromiso con tu futuro" también pueden encontrarse planteamientos en el área económica que apuntan hacia la creación de condiciones para la "estabilidad y el crecimiento", como el desarrollo de infraestructura estratégica para apoyar la producción y la promoción de los recursos naturales, la explotación del mar y de la industria turística.

Lógicamente, los planteamientos de ARENA no han generado hasta ahora ninguna reacción, a favor o en contra, porque no son novedosos y porque, además, no contienen propuestas concretas para alcanzar sus ofrecimientos. Nadie puede cuestionar que un partido se plantee como objetivo "reducir la pobreza al aumentar los ingresos", el problema estriba más bien en la especificación de las medidas con las cuales se alcanzarán los objetivos propuestos. Los planteamientos del FMLN, en cambio, sí se han encontrado rápidamente con la oposición del sector empresarial que los ha calificado de "populistas", "socialistas" y peligrosos para la inversión y el crecimiento económico.

\section{El sector empresarial a la defensiva}

Una de los primeras reacciones provino de $\mathrm{Ra}$ fael Castellanos, director de la Fundación Salvadoreña para el Desarrollo Económico y Social (FUSADES) - la cual puede ser considerada 
como el "tanque" de pensamiento de la empresa privada salvadoreña--, y quien, además, es directivo del banco más importante del país. Obviamente, para Castellanos las propuestas económicas del FMLN "asustan, porque es un retroceso para el país... [y] de llevarse a cabo estancaría al país y espantará a las inversiones que se necesitan para que el país salga adelante"; agregó que "Cuando las tasas de interés se manosean estableciendo un techo, generalmente se presiona a la baja de los intereses para el que ahorra y ello provocaría una fuga de capitales en busca de mejores tasas en el exterior". Finalmente, no dudó en señalar que "Esas son medidas de corte socialista".

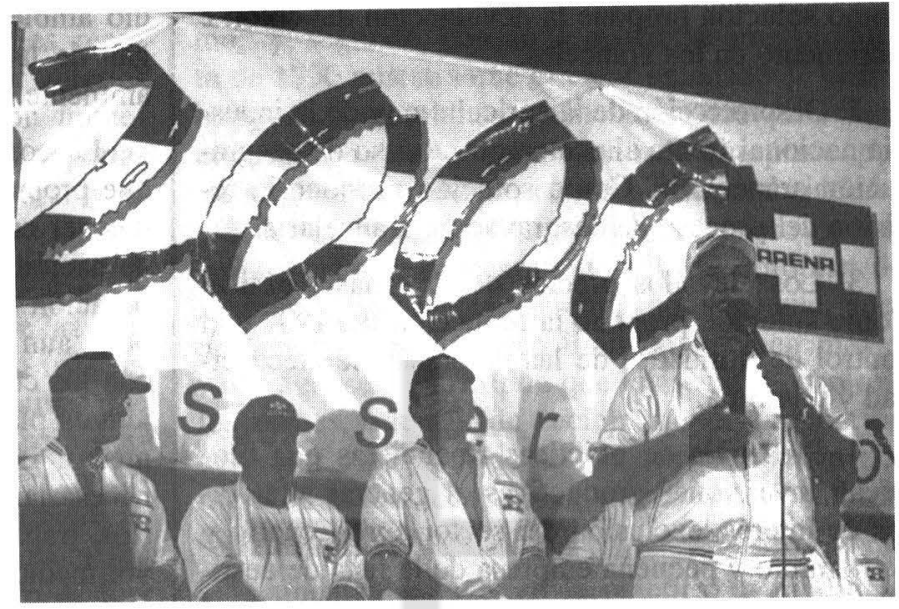

El 23 de febrero, diputados y miembros del FMLN sostuvieron una inusual reunión con los miembros de la Asociación Nacional de la Empresa Privada (ANEP), la cual aglutina a las empresas grandes y gigantes, para presentar su programa legislativo 2000-2003. La reunión, aunque cordial, puso rápidamente en evidencia las discrepancias fundamentales de la ANEP con la propuesta del FMLN. Apenas finalizada la reunión, el presidente de la ANEP, Ricardo Simán, expresó que algunas propuestas son "peligrosas" y podrían provocar desempleo e incrementos en el gasto público y el déficit fiscal. Según Simán, como ANEP "estamos en contra de regulaciones, fijaciones de precios y todo lo que dañe el libre mercado", aunque aceptó que con el FMLN "hay más coincidencias en los problemas que en las soluciones".

La propuesta molestó tanto a la ANEP, que posteriormente difundió un comunicado en el que fijaba su postura frente al planteamiento del FMLN en cinco puntos: aunque reconoce la presencia de problemas económicos, no comparte las propuestas del FMLN para resolverlo; está en contra de cualquier medida que reste libertad y atente contra la libre empresa; la propuesta del FMLN generaría déficit fiscal, inflación, caída de los salarios reales, inestabilidad económica y caída en la inversión; otorgar mayor discrecionalidad a los funcionarios públicos da más espacio para la comupción; y, finalmente, considera que la inversión nacional y extranjera se vería amenazada por medidas "intervencionistas" como las planteadas.

En realidad, esta reacción del sector empresarial no es de extrañar, pues medidas como la fijación de las tasas de interés, la regulación de las ganancias de las empresas de telefonía y electricidad, la reforma tributaria para que paguen "más quienes tienen más ingresos" o la paralización de las privatizaciones, atentan directamente contra los intereses de influyentes sectores empresariales como el sector financiero -integrado orgánicamente al partido ARENA-, las transnacionales y los inversionistas nacionales que se están lucrando de la privatización de la telefonía y de la distribución de electricidad y, en general, todo el sector empresarial que - por percibir mayores ingresos que la mayoría de la población- se vería obligado a pagar mayores impuestos.

Aunque la propuesta de ARENA no ha sido objeto de mayores críticas ni de parte del sector empresarial ni de parte del sector laboral, no por ello puede dejar de notarse que no propone soluciones a las problemáticas actuales, imposibles de ocultar, y que se caracterizan rápidamente a continuación.

\section{Algunos rasgos de la problemática económica} actual

La propuesta del FMLN parece partir, aunque no lo establezca explícitamente, de que los problemas económicos del país y sus respectivas soluciones serían:

1. Estancamiento de las exportaciones y profundización del déficit de la balanza comercial. 
Como solución propone la devaluación del colón e incremento en los aranceles.

2. Desprotección de la agricultura y de la industria nacional frente al acelerado proceso de desgravación arancelaria. Como solución propone la revisión del proceso de desgravación arancelaria.

3. Los elevados precios de la canasta básica. Como solución propone la reducción del IVA y el control de utilidades de las empresas de electricidad y telefonía.

4. Presencia de prácticas financieras que bloquean inversiones productivas al generar altas tasas de interés, exclusión del sector agropecuario y de la micro y pequeña empresa de la lista de destinatarios del crédito. Como solución propone el control directo de las tasas de interés y la creación de líneas especiales de crédito.

5. El bajo nivel salarial de los obreros y trabajadores del campo. Como solución propone incrementos en los salarios mínimos.

6. La profundización del déficit fiscal. Como solución propone más impuestos a las importaciones y a los sectores de mayores ingresos.

7. El elevado déficit en la prestación de servicios sociales básicos. Como solución propone la estabilidad laboral y permanente capacitación de los trabajadores.

8. La desigual distribución del ingreso. Como solución propone que el Estado se encargue de "realizar eficazmente la redistribución del ingreso nacional" y buscar la equidad social.

Cabe destacar que aunque el sector empresarial ha expresado públicamente que comparte el diagnóstico del FMLN, lo más probable es que éste no comparta los dos últimos problemas del listado, pues el sector empresarial siempre se ha mostrado contrario a incrementar las prestaciones laborales y los salarios de los trabajadores.

A esta problemática se agregan otros campos donde la participación del Estado se ha hecho cada vez más urgente: la protección y recuperación del medio ambiente y la concertación de las políticas económicas. El primero es el campo donde más flexibilidad se exige de los modelos neoliberales para aceptar las fuertes regulaciones, draconianas en algunos casos, que los gobiernos suelen imponer. En el caso de Chile, existen cuando menos 1200 cuerpos legales que regulan la protección del me- dio ambiente, mientras 46 instituciones se encargan de la fiscalización de la situación del medio ambiente.

La concertación exige fomentar espacios para que propuestas de diferentes actores sociales puedan ser consensadas y convertidas en un proyecto de nación. Pasos importantes se dieron con la elaboración de las Bases para un plan de nación, pero aún faltan los mecanismos de transmisión con los cuales se podrían alcanzar los grandes objetivos planteados en el recién mencionado documento. La implementación de estos mecanismos necesariamente afecta los intereses de empresarios, trabajadores y gobiemo, pero en mucha mayor medida los de los primeros.

Los acuerdos de paz contemplaron, en 1992, la instalación de un foro de concertación económica y social donde se discutirían políticas y programas económicos, pero este naufragó rápidamente debido a que el sector empresarial se retiró de modo unilateral y, al parecer, en estos momentos hasta al FMLN se le ha olvidado la importancia de estimular el surgimiento de este tipo de espacios. El encuentro del pasado 23 de febrero, entre el sector empresarial y el FMLN, sugiere que el tema de la concertación no ha sido totalmente desechado, pero aún se necesita articular una estrategia de concertación para implementar las medidas económicas que, desafortunadamente, no se percibe en ninguna de las dos plataformas analizadas.

\section{Algunas alternativas de solución}

Para cada uno de los problemas anteriores existen diversidad de posibles soluciones alternativas a las planteadas por el FMLN o a las empleadas por el gobierno, y es aquí donde se encuentran las posibilidades para ir cerrando el abismo entre el modelo neoliberal empresarial, el modelo "altemativo" del FMLN y los objetivos de equidad y crecimiento económico.

A manera de ejemplo pueden citarse algunas medidas con las cuales se pueden solucionar algunos de los problemas específicos señalados en el apartado anterior. El estancamiento de las exportaciones obedece, más que a una apreciación del tipo de cambio, a la ausencia de incentivos para producir exportaciones de mayor valor agregado por lo cual, antes de proceder a una devaluación del colón, es recomendable implementar políticas de incentivos fiscales y crediticios, por ejemplo, que estimulen la 
producción de exportaciones. Inclusive es recomendable retomar planes anunciados por anteriores gobiernos de ARENA que no fueron implementados, como la diversificación de las exportaciones, la reconversión del sector industrial y el plan de desarrollo agropecuario.

En lo tocante al elevado costo de la canasta básica, y más concretamente en el tema de las tarifas telefónicas y del servicio eléctrico, lo más recomendable es promover reformas legislativas que modifiquen sus mecanismos de fijación para permitir una mayor participación de la Superintendencia General de Electricidad y Telecomunicaciones. La reducción del IVA, por otra parte, es totalmente desaconsejable, porque únicamente reduce de forma drástica los ingresos tributarios sin provocar reducciones en los precios.

Los temas relacionados con el sistema financiero pueden abordarse a través de medidas de política monetaria, en el caso de la reducción de las tasas de interés, y con la creación de líneas crediticias especiales para proyectos de inversión de mediana maduración; pero ello necesariamente pasa por que los directivos del sistema financiero se solidaricen con los objetivos del desarrollo y acepten su importante rol de intermediarios financieros que promueven la captación de ahorro y lo canalizan hacia inversiones productivas.

Los aspectos relacionados con la distribución del ingreso y las prestaciones sociales merecen ser objeto de mayor discusión, pero es difícil negar que se vuelve totalmente necesario trasladar recursos desde los sectores de mayores ingresos hacia los de menores ingresos, que no están siquiera en capacidad de satisfacer sus necesidades básicas. Aun partiendo del supuesto de que será el crecimiento de la producción, el empleo y el ingreso lo que finalmente generará bienestar, siempre será necesario contemplar planes complementarios, que busquen cubrir los déficit sociales. Lo anterior supone, cuando menos, que se consideren medidas como el incremento de los impuestos a los sectores de mayores ingresos, a través de reformas al impuesto sobre la renta y, en segundo lugar, la alteración de la estructura de distribución del valor agregado.

Estas medidas son teóricamente viables; primero, porque los sectores de mayores ingresos pagan ahora menos impuestos debido a que se ha reducido a la mitad el impuesto sobre la renta de las empresas y se eliminó el impuesto al patrimo- nio; y, segundo, porque la matriz insumo-producto de 1990 muestra que el valor agregado se distribuye desproporcionadamente entre los diferentes actores sociales (60 por ciento es apropiado por los empresarios, 30 por ciento por los trabajadores y 5 por ciento por el Estado, en concepto de impuestos). Los empresarios no sólo se apropian de la mayor parte del valor agregado, sino que, además, por ser un número limitado, reciben mayor valor agregado per cápita que los sectores obreros, los cuales, además de recibir menor proporción del valor agregado, deben repartirlo entre un número de asalariados abismalmente superior al número de empresarios.

Lamentablemente, en la práctica, la modificación de la distribución del valor agregado no es viable en el momento actual, debido a la férrea e ideologizada postura del sector empresarial a favor de la eliminación absoluta de las regulaciones estatales y en contra del incremento de las funciones sociales y redistributivas del Estado. Tarde o temprano, el sector empresarial deberá aceptar las imperfecciones del libre mercado y la necesidad de que el Estado desempeñe un fuerte y bien planificado rol de regulador, promotor y orientador del desarrollo sostenible. Por el bien de los salvadoreños, esperamos que decida hacerlo más temprano que tarde y así evitar la gestación de guerras civiles o de condiciones sociales que estimulen, aún más, el incremento de la violencia social.

\section{Consideraciones}

La propuesta del FMLN presenta varias inconsistencias en lo referente a las medidas "urgentes" y a las de mediano plazo. Por ejemplo, la devaluación del colón provocará incrementos en las tasas de inflación sin que necesariamente por ello se registren incrementos en las exportaciones, tal como lo propone el FMLN; de la misma manera, una reducción del IVA del 10 al 13 por ciento reducirá los ingresos tributarios sin que necesariamente se registren reducciones en los precios al consumidor, que es quien paga el IVA.

Las inconsistencias también están presentes en la propuesta de ARENA y surgen de la pretensión de desarrollar el agro para reducir la pobreza sin una política sectorial clara, y en un contexto donde la liberalización económica está conduciendo a la crisis del sector. Adicionalmente, ARENA rehusa tocar el meollo del tema de las finanzas públicas: la necesidad de incrementar los impuestos a 
los sectores de mayores ingresos. La reducción o incluso la eliminación de la elusión y la evasión fiscal podría conducir a mayores niveles de recaudación y a una eventual eliminación del déficit fiscal; sin embargo, no queda claro cómo se fínanciarán los necesarios incrementos en la provisión de servicios de educación y salud que se requieren en la actualidad, los cuales crecen conjuntamente con la población y son indispensables para generar los "empleos e ingresos" necesarios para reducir la pobreza.

La propuesta del FMLN es, sin duda, la más polémica de las dos examinadas porque propone tres medidas que afectan los intereses de los grandes empresarios: fijación de las tasas de interés, suspensión de los procesos de privatización y regulación de las ganancias de las empresas. Sin embargo, la verdad es que difícilmente se avanzará en la senda del desarrollo exclusivamente a partir de políticas de liberalización de mercados, pues la misma práctica y realidad internacional muestran que también es necesario implementar políticas sociales que potencien las oportunidades de inserción en el mercado internacional y que permitan regular algunos mercados, cuya dinámica esté en contradicción con objetivos superiores a la mera liberalización económica.

De hecho, el objetivo último de la política económica no es la promoción del libre mercado, sino la búsqueda del desarrollo sostenible, pues, en muchos casos, la ausencia de regulaciones estatales conduce a problemas como los que se viven actualmente en El Salvador y que, necesariamente, requieren acciones definidas $y$ decididas para su corrección. La postura de la empresa privada frente al tema de la regulación estatal, independiente- mente de las propuestas concretas del FMLN, es absoluta y no deja espacio para ningún tipo de regulación, por mínima que ésta sea. Paradójicamente, inclusive en los países que se consideran como los de mayor libertad económica, existen regulaciones sobre las tasas de interés, las actividades monopólicas y todas aquellas prácticas empresariales que atenten contra los derechos del consumidor, para mencionar algunos ejemplos.

Es innegable que para alcanzar el desarrollo sostenible se necesita de un mayor sacrificio del sector empresarial, pues hasta ahora han sido los consumidores y trabajadores los que han cargado con el mayor peso del ajuste, mientras unos pocos grandes empresarios se han aprovechado de las oportunidades abiertas por la liberalización de los mercados y la privatización. Aunque no todas las medidas del FMLN puedan ser las más indicadas para enfrentar la situación económica actual, han puesto de nuevo sobre el tapete el tema del papel del Estado en la economía, sugiriendo que es necesario que éste desempeñe un papel protagónico en la regulación de la economía allí donde las fuerzas del mercado se opongan a los objetivos del desarrollo sostenible.

No es cierto que en El Salvador se estén proponiendo medidas de corte "socialista" o que resulten "aberrantes" en otros países con economías liberalizadas. De hecho, las transnacionales de teléfonos y electricidad están más desreguladas en El Salvador que en Chile y, por tanto, no habría que rasgarse las vestiduras cuando alguien proponga mayores regulaciones económicas; a menos que se pretenda ser más liberal que Milton Friedman.

Luis Ernesto Romano 